Jurnal CARE, Vol. 2, No. 2, 2014

\title{
HUBUNGAN ANTARA DUKUNGAN KELUARGA DENGAN TINGKAT KECEMASAN PADA MAHASISWA YANG MENGERJAKAN SKRIPSI DI PROGRAM STUDI ILMU KEPERAWATAN UNIVERSITAS TRIBHUWANA TUNGGADEWI MALANG
}

\author{
Lasri ${ }^{1)}$ \\ Kartika Ratih Pratiwi 2) \\ 1), 2) Program Studi Ilmu Keperawatan, Fakultas Ilmu Kesehatan \\ Universitas Tribhuwana Tunggadewi Malang \\ email: mrs.lasri1956@gmail.com
}

\begin{abstract}
The anxiety is very disturbing homeostasis and the function of individual, because it needs to be removed with the various ways of adjustment. When the students experience the anxiety in the thesis working, support is useful to face the anxiety. The purpose of this study is to analyze the relationship between family support with the level of anxiety of students who worked the thesis in Nursing Science Program, University of Tribhuwana Tunggadewi Malang Year 2009. This study uses a correlational research design with cross sectional method. With total of sample 30 people that were taken by Simple Random Sampling. Instrument used was a questionnaire. The collection data were analyzed using Spearman's rho test with $a=0.05$. From the result of study was obtained that most of respondents have a good family support with a number 19 people (63.3\%), the anxiety level of most respondents is the medium anxiety level with a number 17 people (56.7\%). The result of analysis shows the value of Sig. 2 tailed $0.000<$ a 0.05 and Correlation Coefficient 0.809, so there is a very strong relationship between the family support with the levels of anxiety. It si recommended to establish the educational guidance, support and motivation so the students do not experience the excessive anxiety when worked the thesis.
\end{abstract}

Keywords: Family Support, The Anxiety Level

\section{PENDAHULUAN}

Menurut Carpenito (dalam Pamungkas, 2011) kecemasan adalah gejala yang tidak spesifik dan aktivitas saraf otonom dalam berespon terhadap ketidakjelasan, ancaman tidak spesifik yang sering ditemukan dan sering kali merupakan suatu emosi yang normal. Kecemasan dapat disebabkan oleh beberapa faktor diantaranya patofisiologis dan situasional (Carpenito, 2000). Kecemasan sangat mengganggu homeostasis dan fungsi individu, karena itu perlu segera dihilangkan dengan berbagai macam cara penyesuaian (Maramis, 2005).

Kecemasan merupakan gangguan mental terbesar. Diperkirakan $20 \%$ dari populasi dunia menderita kecemasan menurut Gail (dalam Ermawati, 2012) dan sebanyak 47,7\% remaja sering merasa cemas menurut Haryadi (dalam Ermawati, 2012). Indonesia merupakan negara berkembang, dimana setiap tahunnya angka kecemasan semakin meningkat, prevalensi keadaan kecemasan (anxietas) di Indonesia berkisar antara 2-5\% dari populasi umum atau $7-16 \%$ dari semua penderita gangguan jiwa menurut Pietra (dalam Ermawati, 2012). Seperti halnya mahasiswa pun tidak luput dari kecemasan, salah satu yang menjadi stresor dalam kehidupan mahasiswa adalah tuntutan dalam mengerjakan skripsi sehingga harus menyelesaikan sesuai target juga menjadi salah satu faktor pencetus kecemasan pada mahasiswa.

Skripsi adalah suatu karya ilmiah hasil penelitian mandiri atau kajian kepustakaan dengan bantuan seorang dosen pembimbing yang dikerjakan untuk memperoleh gelar sarjana (jenjang S1) dan telah berhasil dipertahankan dihadapan suatu tim penguji yang dibentuk oleh perguruan tinggi. Skripsi adalah karya ilmiah yang ditulis melalui kegiatan perencanaan, pelaksanaan dan hasil penelitian ilmiah oleh mahasiswa jenjang program sarjana muda atau sarjana. Skripsi dapat merupakan tugas akhir bagi mahasiswa untuk mencapai gelar kesarjanaannya (Setiadi, 2007).

Skripsi seringkali ditanggapi serius oleh mahasiswa untuk itu mereka menyiapkan diri baik fisik maupun non fisik agar mereka terhindar dari kegagalan dalam skripsi. Jika mereka mengalami kegagalan dalam skripsi tersebut, maka mereka akan memikul beban moral seperti rasa malu, canggung, minder dan menghindari pergaulan yang pada akhirnya mereka akan kehilangan rasa percaya diri. Perasaan takut gagal tersebut dapat menjadi 
Jurnal CARE, Vol. 2, No. 2, 2014

beban yang menyebabkan para siswa memiliki kecemasan dalam menghadapi skripsi.

Menurut Sarason, dkk (Djiwandono, 2002 dalam Fitria, 2007) ada beberapa faktor yang dapat mempengaruhi kecemasan yaitu keyakinan diri, dukungan sosial dan modelling. Dukungan keluarga adalah sikap dan tindakan yang dilakukan keluarga (orang tua, saudara, suami, istri dan anak) dalam keluarga inti terdiri dari memberi informasi, nasehat verbal dan bantuan nyata (Gottlieb dalam Suparyanto, 2012). Ketika mahasiswa mengalami kecemasan dalam mengerjakan skripsi, dukungan berguna untuk menghadapi cemas. Dukungan keluarga merupakan dukungan sosial pertama yang diterima karena keluarga adalah orang yang paling dekat dengan individu dan memiliki peluang paling besar untuk memberi bantuan. Adanya dukungan keluarga menjadikan mahasiswa lebih semangat dalam mengerjakan skripsi. Tujuan dari dukungan keluarga untuk meredakan cemas dan memberikan ketenangan.

Berdasarkan studi pendahuluan pada tanggal 24 Mei 2013 di Program Studi Ilmu Keperawatan Universitas Tribhuwana Tunggadewi Malang dengan wawancara kepada mahasiswa sebanyak 10 mahasiswa, tentang apa yang dirasakan mahasiswa menjelang skripsi/ujian proposal yang sudah dekat waktunya, didapatkan hasil sebagai berikut: 2 mahasiswa menyatakan sulit tidur, 4 mahasiswa menyatakan tidak tenang atau gugup, 3 mahasiswa menyatakan perhatian terganggu dan 1 menyatakan respon biasa. Dari hasil wawancara tersebut ternyata $90 \%$ mahasiswa yang mengerjakan skripsi mengalami kecemasan. Dan dari 10 mahasiswa tersebut, 9 mahasiswa jauh dari keluarga yang mana mereka tinggal di kos-kosan sedangkan 1 orang mahasiswa tinggal bersama keluarga. Dari hasil tersebut di dapatkan juga 8 mahasiswa menyatakan mendapatkan perhatian dari keluarga dan sering berkomunikasi dengan keluarga, 2 mahasiswa menyatakan kurang berkomunikasi dengan keluarga dan kurang mendapatkan perhatian dari keluarga.

Dari uraian diatas, peneliti tertarik ingin melakukan penelitian dengan judul "Hubungan Antara Dukungan Keluarga Dengan Tingkat Kecemasan Pada Mahasiswa Yang Mengerjakan Skripsi Di Program Studi Ilmu Keperawatan Universitas Tribhuwana Tunggadewi Malang “.

\section{METODE PENELITIAN}

Dharma (2011) menyebutkan, desain penelitian adalah model atau metode yang bertujuan untuk menentukan arah penelitian. Penelitian ini termasuk penelitian yang menggunakan metode korelasional yaitu mengkaji hubungan antar variabel dimana peneliti dapat mencari, menjelaskan suatu hubungan, mengamati, menguji berdasarkan teori yang ada. Penelitian korelasional bertujuan mengungkapkan hubungan korelatif antar variabel (Nursalam, 2008). Pendekatan yang digunakan dalam penelitian ini adalah cross sectional yaitu rancangan penelitian dengan melakukan pengukuran atau pengamatan pada saat bersamaan (sekali waktu) (Hidayat,2009).

Penelitian ini dilakukan di Program Studi Ilmu Keperawatan Universitas Tribhuwana Tunggadewi Malang dengan populasi berjumlah 98 orang dan sampel yang digunakan 30 orang dengan menggunakan simple random sampling. Pengumpulan data yang digunakan dengan kuesioner. Instrumen untuk mengukur variabel independen yaitu dukungan keluarga menggunakan kuesioner yang di buat sendiri oleh peneliti berdasarkan definisi operasional dengan jumlah pertanyaan 12 pertanyaan dan untuk variabel dependen yaitu tingkat kecemasan menggunakan skala HARS yang sudah baku dengan jumlah pertanyaan 14 pertanyaan.

Dalam penelitian ini analisa data yang digunakan adalah uji Spearman Rank yang menggunakan bantuan SPSS for window versi 17 dengan taraf signifikan $(\alpha=0,05)$, dengan interpretasi nilai $\alpha<0,05$ artinya H1 diterima yaitu ada hubungan antara variabel dependen dan variabel independen. Apabila $\alpha>0,05$ artinya $\mathrm{H} 1$ ditolak yaitu tidak ada hubungan antara variabel dependen dan variabel independen (Hidayat, 2009).

\section{HASIL DAN PEMBAHASAN}

Berdasarkan hasil penelitian yang dilakukan diketahui bahwa mahasiswa yang mempunyai dukungan keluarga baik sebanyak 19 orang $(63,3 \%)$, dukungan keluarga sedang sebanyak 7 orang $(23,3 \%)$, dan dukungan keluarga kurang sebanyak 4 orang (13,3\%). Dan untuk penelitian tingkat kecemasan ini membuktikan bahwa responden yang didapatkan yang mengalami tingkat kecemasan sedang sebanyak 17 orang (56,7\%), yang mengalami tingkat kecemasan ringan sebanyak 8 orang $(26,7 \%)$, dan yang tidak mengalami kecemasan sebanyak 5 orang $(16,7 \%)$. 
Jurnal CARE, Vol. 2, No. 2, 2014

Penelitian ini mendapatkan hasil ada hubungan yang signifikan antara dukungan keluarga dengan tingkat kecemasan yang dibuktikan dengan nilai $\mathrm{p}$ value sebesar 0,000 $<\alpha$ 0,05. Berdasarkan hasil uji statistik besarnya hubungan antara dukungan keluarga dengan tingkat kecemasan adalah 0,809 atau $80,9 \%$ yang mana hubungan tersebut masuk pada kategori hubungan yang sangat kuat.

\section{KESIMPULAN}

Sebagian responden mempunyai dukungan keluarga baik sebanyak 19 orang $(63,3 \%)$. Dan untuk tingkat kecemasan sebagian besar responden mengalami tingkat kecemasan sedang sebanyak 17 orang $(56,7 \%)$. Hasil uji statistik diketahui tingkat signifikan sebesar $0,000<0,05$ berarti ada hubungan yang sangat kuat antara dukungan keluarga dengan tingkat kecemasan pada mahasiswa PSIK UNITRI Malang angkatan 2009.

\section{UCAPAN TERIMA KASIH}

Terima kasih disampaikan kepada mahasiswa angkatan 2009 Program Studi Ilmu Keperawatan Fakultas Ilmu Kesehatan Universitas Tunggadewi Malang yang telah berpartisipasi dalam penelitian ini serta pihakpihak yang telah memberikan ijin dalam pelaksanaan penelitian.

\section{DAFTAR PUSTAKA}

Carpenito, L.J., 2000. Buku Saku Diagnosa Keperawatan (Terjemahan). Edisi 8. EGC. Jakarta.

Dharma, K. (2011) Metodologi Penelitian Keperawatan. Jakarta: Penerbit Buku Kesehatan.

Ermawati. 2012. Pengaruh Psikoreligius Terhadap Tingkat Kecemasan Pada Mahasiswa Yang Mengerjakan Skripsi Di Program Studi Ilmu Keperawatan Universitas Tribhuwana Tunggadewi Malang. Skipsi Fakultas Ilmu Kesehatan Tribhuwana Tunggadewi Malang.

Hidayat, A.A.A. 2009. Metode Penelitian Keperawatan Dan Teknik Analisis Data. Salemba Medika. Surabaya.

Linayaningsih, F. 2007. Kecemasan Pada Mahasiswa Fakultas Psikologi Universitas Katolik Soegijapranata Dalam Mengerjakan Skripsi. Skripsi Fakultas Psikologi
Universitas Katolik Soegijapranata Semarang.

Maramis, W. F. 2005. Demensi Religi Dalam Praktek Psikiatrikdan Psikologi. FKUI. Jakarta.

Nursalam. 2008. Konsep dan Penerapan Metodeleogi Penelitian Ilmu Keperawatan. Edisi 2. Jakarta: Salemba Medika.

Pamungkas, Gunawan. 2011. Konsep Kecemasan http://.www teorikecemasan.blogspot.com. Diakses pada tanggal 17 maret 2013. Jam 18.30 WIB

Setiadi. 2007. Konsep Dan Riset Keperawatan. Edisi 1. Graha Ilmu. Yogyakarta.

Suparyanto. Konsep Dukungan Keluarga. http://belajarpsikologi.com. Diakses pada tanggal 22 Mei 2013. Jam 19.00 WIB 